\title{
Preparation and properties of Nd,Yb:GGG polycrystalline nanopowders
}

\author{
Yanmin DONG, Jing SUN*, Wensheng YU, Weihang LI, Fei TENG \\ School of Chemistry and Environmental Engineering, Changchun University of Science and Technology, \\ Changchun 130022, China
}

Received: September 26, 2012; Revised: November 29, 2012; Accepted: December 1, 2012

(C) The Author(s) 2012. This article is published with open access at Springerlink.com

\begin{abstract}
Gadolinium gallium garnet (GGG) polycrystalline powders doped with $\mathrm{Nd}, \mathrm{Yb}$ were prepared by co-precipitation method. The structure, phase and properties of powders were characterized by X-ray diffraction (XRD), Fourier transform infrared spectroscopy (FTIR), scanning electron microscope (SEM), energy dispersive X-ray spectroscopy (EDS) and fluorescence spectroscopy. XRD analysis indicated that the crystallization of Nd,Yb:GGG powders occur at $900{ }^{\circ} \mathrm{C}$. SEM analysis showed that the morphology of the powders was irregular and the average radius is $68.74 \mathrm{~nm}$. FTIR analysis manifested that pure Nd,Yb:GGG powders were formed at $900{ }^{\circ} \mathrm{C}$. The fluorescence spectrum revealed that the most strong emission of Nd,Yb:GGG powders was $1030 \mathrm{~nm}$, which was attributed to ${ }^{2} \mathrm{~F}_{5 / 2} \rightarrow{ }^{2} \mathrm{~F}_{7 / 2}$ of $\mathrm{Yb}^{3+}$. The possible formation mechanism of $\mathrm{Nd}, \mathrm{Yb}$ :GGG powders were preliminarily discussed.
\end{abstract}

Key words: Nd,Yb:GGG; co-precipitation method; fluorescence

\section{Introduction}

In the latest years, gadolinium gallium garnet (GGG) polycrystalline nanopowders have attracted great interest due to their high performance in technological applications [1-5]. Various methods have been explored to synthesize gadolinium gallium garnet (GGG) polycrystalline powders, such as solid-state method, sol-gel, hydrothermal method etc. However, the methods mentioned above had some disadvantages, such as the solid-state method required high tempreture, the low productivity of the hydrothermal method and

* Corresponding author.

E-mail: sj-cust@126.com the sol-gel method required expensive equipments. For liquid-phase co-precipitation method, the GGG polycrystalline powders with pure phase could be obtained in the lower sintered temperature and for shorter time $(4 \mathrm{~h})$, because the co-precipitation increased the activity of GGG synthesis reaction [6].

The ytterbium ion consisting only two energy levels: the ${ }^{2} \mathrm{~F}_{5 / 2}$ excited state and the ${ }^{2} \mathrm{~F}_{7 / 2}$ ground state, since the simplest energy level scheme, it is suited for diode pumping. In addition, the intense and broad $\mathrm{Yb}^{3+}$ absorption lines are well suited for infrared InGaAs diode laser pumping, the broad emission band allows the generation of ultra-short pulses and the small quantum defect between absorption and emission wavelengths, leads to a low thermal load $[7,8]$. The neodymium multiple excited states with high 
absorption cross-section that it could be used for pulse pumping. The $\mathrm{Nd}-\mathrm{Yb}$ energy transfer was very efficient because the system combine the $\mathrm{Yb}^{3+}$ good laser emission characterristics and the $\mathrm{Nd}^{3+}$ multiple excited states.

In this paper, Nd,Yb:GGG polycrystalline powders were fabricated by co-precipitation method. The morphology and luminescence characteristics of $\mathrm{Nd}, \mathrm{Yb}: G G G$ polycrystalline powders and $\mathrm{Nd} \rightarrow \mathrm{Yb}$ energy transfer were investigated.

\section{Experimental details}

\subsection{Chemicals}

The aqueous ammonia was purchased from Tianjin Tiantai Fine Chemical Reagents Co. Ltd. and $\mathrm{HNO}_{3}$ was bought from Beijing Chemical Company. $\mathrm{Yb}_{2} \mathrm{O}_{3}$ (99.99\%), $\mathrm{Ga}_{2} \mathrm{O}_{3}(99.99 \%), \mathrm{Nb}_{2} \mathrm{O}_{3}$ and $\mathrm{Gd}_{2} \mathrm{O}_{3}$ were bought from Sinopharm Chemical Reagents Co. Ltd. $\mathrm{Yb}\left(\mathrm{NO}_{3}\right)_{3}, \mathrm{Ga}\left(\mathrm{NO}_{3}\right)_{3}, \mathrm{Nb}\left(\mathrm{NO}_{3}\right)_{3}$ and $\mathrm{Gd}\left(\mathrm{NO}_{3}\right)_{3}$ were prepared by dissolving $\mathrm{Yb}_{2} \mathrm{O}_{3}, \mathrm{Ga}_{2} \mathrm{O}_{3}, \mathrm{Nb}_{2} \mathrm{O}_{3}$ and $\mathrm{Gd}_{2} \mathrm{O}_{3}$ in dilute nitric acid, then the solution was heated to evaporat the water. All chemicals were of analytical grade and directly used as received without further purification.

\subsection{Preparation of samples}

$\mathrm{Yb}_{2} \mathrm{O}_{3}, \mathrm{Ga}_{2} \mathrm{O}_{3}, \mathrm{Nb}_{2} \mathrm{O}_{3}$ and $\mathrm{Gd}_{2} \mathrm{O}_{3}$ in a specific stoichiometric molar ratio were separately dissolved in nitric acid and the resulting solutions were mixed and stirred at room temperature. The resulting solution was slowly added dropwise into aqueous ammonia under constant stirring, keeping the $\mathrm{pH}$ around 9.0. The gelatinous white co-precipitate of gallium-gadolinium hydroxide with $\mathrm{Nb}, \mathrm{Yb}$ was filtered, washed several times with distilled water to remove the residual nitrate ions, and finally oven dried at $60{ }^{\circ} \mathrm{C}$ to obtain the precursor powders. Selected portions were later calcination at $700{ }^{\circ} \mathrm{C}$ and $900{ }^{\circ} \mathrm{C}$ for $4 \mathrm{~h}$ in a muffle furnace under air atmosphere.

\subsection{Characterization methods}

X-ray powder diffraction (XRD) measurements were carried out on a MXP21VAHF diffractometer using $\mathrm{CuK}_{\alpha}$ radiation with $\mathrm{Ni}$ filter $(\lambda=0.15405 \mathrm{~nm})$. The $\mathrm{X}$-ray generator worked at a power of $40 \mathrm{kV}$ and $40 \mathrm{~mA}$. Fourier transform infrared spectroscopy (FTIR) was recorded on BRUKER Vertex 70. Fourier transform infrared spectrometer was made by Germany Bruker Company with a resolution of $1 \mathrm{~cm}^{-1}$, and the specimen for the measurement was prepared by mixing the sample with $\mathrm{KBr}$ powders. Then the mixture was pressed into pellets, and the spectrum was acquired in a wave number range from $4000 \mathrm{~cm}^{-1}$ to $400 \mathrm{~cm}^{-1}$. Scanning electron microscope (SEM) images were taken with Jeol (Tokyo, Japan) JSM 5600. Samples were coated with a $\mathrm{Au}$ thin film, in order to avoid charging effects. The fluorescence measurements were performed on a Hitachi F-7000 spectrophotometer equipped with a $150 \mathrm{~W}$ argon lamp as the excitation source.

\section{Results and discussion}

\subsection{XRD patterns}

The X-ray diffraction patterns of $\mathrm{Nd}, \mathrm{Yb}$ :GGG samples which were calcined at $700{ }^{\circ} \mathrm{C}$ and $900{ }^{\circ} \mathrm{C}$ were showed in Fig. 1. There was a broad peak around $32^{\circ}$ for the composite powders, indicating that the samples were amorphous. However, when calcined after $900{ }^{\circ} \mathrm{C}$, all the reflection peaks can be readily indexed to those of the pure cubic phase with primitive structure of GGG (PDF\#13-0493), indicating that the pure phase of $\mathrm{Nd}, \mathrm{Yb}$ :GGG polycrystalline powders was successfully prepared, its space group is $\mathrm{I}_{\mathrm{a}} 3 \mathrm{~d}$. Also, the structure of GGG was not changed when $\mathrm{Nd}^{3+}$ and $\mathrm{Yb}^{3+}$ were doped.



Fig. 1 XRD of $\mathrm{Nd}, \mathrm{Yb}$ :GGG polycrystalline powders.

\subsection{FTIR spectra analysis}

$\mathrm{Nd}, \mathrm{Yb}$ :GGG sample without calcination and the one 
calcined at $900{ }^{\circ} \mathrm{C}$ were investigated by FTIR, as shown in Fig. 2. All the absorption peaks at about $3200-3700 \mathrm{~cm}^{-1}$, corresponding to the stretching vibrations of hydroxyl group ( $\mathrm{v}_{\mathrm{O}-\mathrm{H}}$ ) and $\mathrm{C}-\mathrm{H}$ bond $\left(\mathrm{v}_{\mathrm{C}-\mathrm{H}}\right)$, respectively. All the absorption peaks at about $1653 \mathrm{~cm}^{-1}$ and $1537 \mathrm{~cm}^{-1}$ were attributed to the combination of the carbonyl group $\left(\mathrm{v}_{\mathrm{C}=\mathrm{O}}\right)$, hydroxyl group $\left(\mathrm{v}_{\mathrm{O}-\mathrm{H}}\right)$ and $\mathrm{C}-\mathrm{H}$ bond $\left(\mathrm{v}_{\mathrm{C}-\mathrm{H}}\right)$. All the absorption peaks weakened or disappeared and new absorption peaks appeared at low wave numbers after calcined at $900{ }^{\circ} \mathrm{C}$ (as shown in Fig. 2(b)). The peaks at $3467 \mathrm{~cm}^{-1}$ and $2367 \mathrm{~cm}^{-1}$ were attributed to the $\mathrm{H}_{2} \mathrm{O}$ and $\mathrm{CO}_{2}$ from ambient atmosphere. The weak peaks at $1644 \mathrm{~cm}^{-1}$ indicated that there was still a few of $-\mathrm{NH}_{2}$ in the powders. The peaks at $1399 \mathrm{~cm}^{-1}$ were attributed to the stretching vibrations of few $\mathrm{C}-\mathrm{O}$ bond $\left(\mathrm{v}_{\mathrm{C}-\mathrm{O}}\right)$ and $\mathrm{C}-\mathrm{C}$ bond $\left(\mathrm{v}_{\mathrm{C}-\mathrm{C}}\right)$. The new peaks at $612 \mathrm{~cm}^{-1}$ and $464 \mathrm{~cm}^{-1}$ were associated with the metal-oxygen bonds (Gd-O and Gd-O-Ga) vibrations. FTIR analysis manifested that pure GGG polycrystalline powders

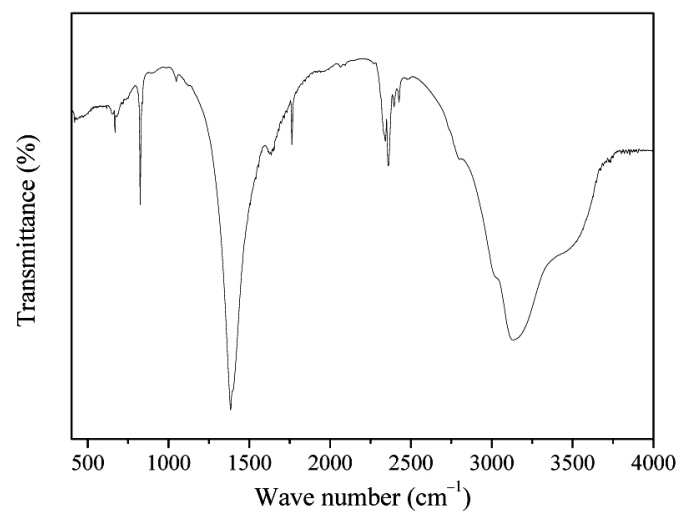

(a) The sample without calcination

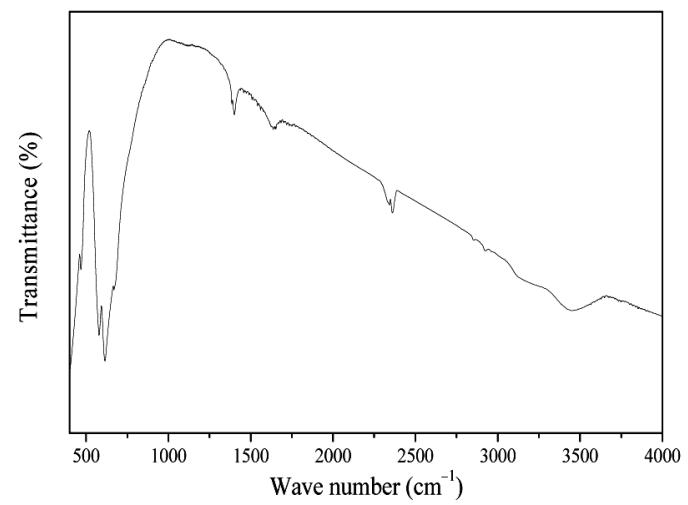

(b) $\mathrm{Nd}, \mathrm{Yb}$ :GGG polycrystalline powders calcined at $900{ }^{\circ} \mathrm{C}$

Fig. 2 FTIR spectra of Nd,Yb:GGG polycrystalline powders. were formed at $900{ }^{\circ} \mathrm{C}$, and the peaks were sharp and obvious. The results were in good agreement with XRD patterns.

\subsection{SEM analysis}

Figure 3 showed the SEM images of $\mathrm{Nd}, \mathrm{Yb}$ :GGG polycrystalline powders calcined at $900{ }^{\circ} \mathrm{C}$. The morphology of the Nd,Yb:GGG samples was irregular agglomeration of small crystallites. Figure 4 showed the particle size distribution histograms of the $\mathrm{Nd}, \mathrm{Yb}$ :GGG samples. The particle size distribution histograms showed the average diameter of the samples was $68.74 \mathrm{~nm}$.

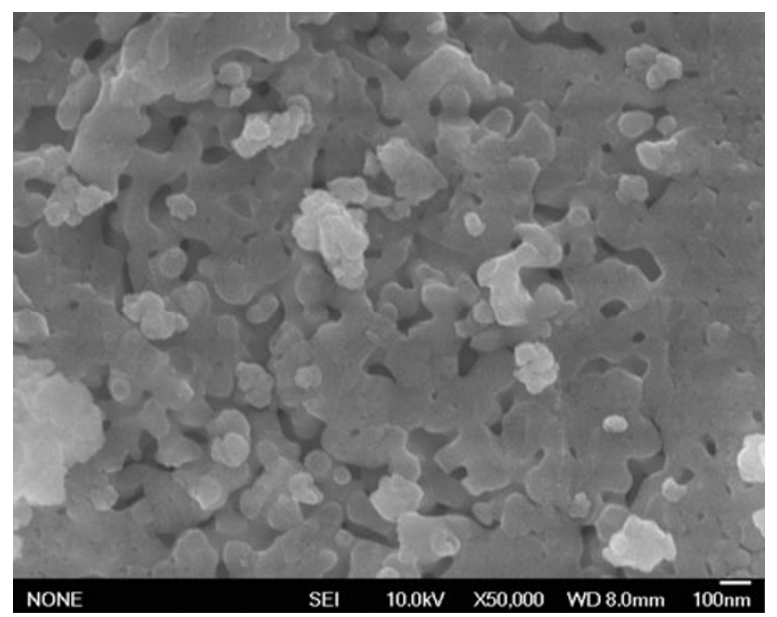

Fig. 3 SEM of Nd,Yb:GGG polycrystalline powders.

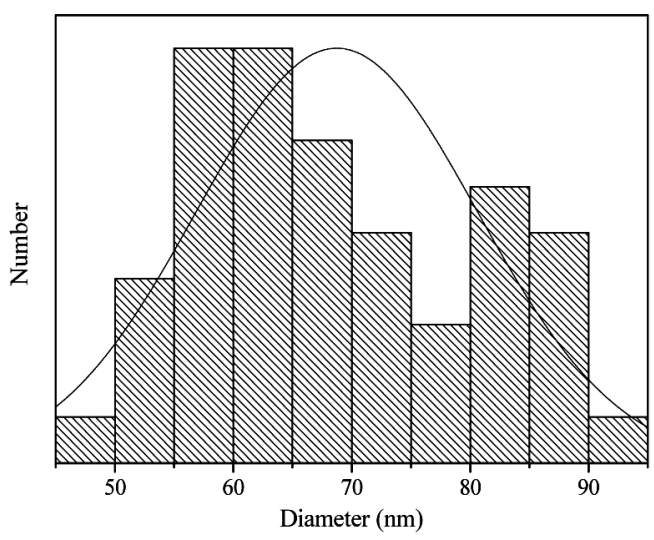

Fig. 4 Particle size distribution histograms.

\subsection{EDS analysis}

Figure 5 showed the EDS of Nd,Yb:GGG polycrystalline powders, demonstrating that the elements of $\mathrm{Yb}, \mathrm{O}, \mathrm{Ga}, \mathrm{Gd}$ and $\mathrm{Nd}$ were existed in the powders. 


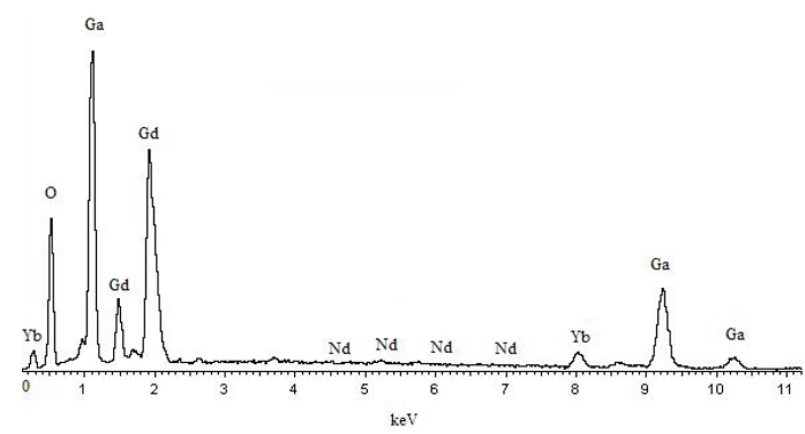

Fig. 5 EDS of Nd,Yb:GGG polycrystalline powders.

\subsection{Photoluminescence properties}

Figure 6 showed the fluorescence spectrum of $\mathrm{Nd}, \mathrm{Yb}$ :GGG polycrystalline powders excited with argon ion laser at $488 \mathrm{~nm}$. Between the waves at $900-1100 \mathrm{~nm}$ (the wavenumber was between $11111.1 \mathrm{~cm}^{-1}$ and $9090.9 \mathrm{~cm}^{-1}$ showed in Fig. 6), there were two emission peaks with $977 \mathrm{~nm}$ (the wavenumber was $10235.4 \mathrm{~cm}^{-1}$ ) and $1030 \mathrm{~nm}$ (the wavenumber was $9708.7 \mathrm{~cm}^{-1}$ ). The third one was at $1075 \mathrm{~nm}$ (the wavenumber was $9302.3 \mathrm{~cm}^{-1}$ ). The strongest emission peak at $1030 \mathrm{~nm}$ was assigned to the ${ }^{2} \mathrm{~F}_{5 / 2} \rightarrow{ }^{2} \mathrm{~F}_{7 / 2}$ transition of $\mathrm{Yb}^{3+}$. Analysis with the $\mathrm{EDS}$, the $\mathrm{Nd}$ and $\mathrm{Yb}$ were exactly coexistence. However, Fig. 6 only showed the emission of $\mathrm{Yb}^{3+}$, but the emission of $\mathrm{Nd}^{3+}$ was not showed. It indicated that in the process of emission, the $\mathrm{Nd}^{3+}$ gained energy and also transfered the energy to $\mathrm{Yb}^{3+}[9,10]$.



Fig. 6 Fluorescence spectrum of $\mathrm{Nd}, \mathrm{Yb}: \mathrm{GGG}$ polycrystalline powders.

\subsection{The energy transfer of $\mathrm{Nd}, \mathrm{Yb}$}

$\mathrm{The} \mathrm{Nd} \rightarrow \mathrm{Yb}$ energy transfer in GGG involves $\mathrm{Nd}^{3+}$ $\left({ }^{4} \mathrm{~F}_{3 / 2} \rightarrow{ }^{4} \mathrm{I}_{9 / 2}\right) \quad$ emission and $\quad \mathrm{Yb}^{3+} \quad\left({ }^{2} \mathrm{~F}_{7 / 2} \rightarrow{ }^{2} \mathrm{~F}_{5 / 2}\right)$ absorption. The large crystal field splittings of the levels assure the overlap of the $\mathrm{Nd}^{3+}\left({ }^{4} \mathrm{~F}_{3 / 2} \rightarrow{ }^{4} \mathrm{I}_{9 / 2}\right)$ emission with $\mathrm{Yb}^{3+}\left({ }^{2} \mathrm{~F}_{7 / 2} \rightarrow{ }^{2} \mathrm{~F}_{5 / 2}\right)$ absorption. The resonant ET rates are proportional to the integral overlap of the experimental normalized line shapes $g(E)=\sigma(E) / \int \sigma(E) \mathrm{d} E \frac{n !}{r !(n-r) !}$ of the $\mathrm{Nd}^{3+}$ emission and $\mathrm{Yb}^{3+}$ absorption, $W \propto \int g_{\mathrm{Nd}}^{e m}(E) / g_{\mathrm{Yb}}^{a b s}(E) \mathrm{d} E$ [11]. Figure 7 showed the scheme of energy transfer for $\mathrm{Nd}^{3+}$ and $\mathrm{Yb}^{3+}$. The non-radiation energy transfer passed the energy to $\mathrm{Yb}^{3+}$ through the transition of $\mathrm{Nd}^{3+}$ from excited state to the ground state. The fluorescence emission was caused by the ${ }^{2} \mathrm{~F}_{5 / 2} \rightarrow{ }^{2} \mathrm{~F}_{7 / 2}$ radiation transition of $\mathrm{Yb}^{3+}$. Because there is no overlap between $\mathrm{Yb}^{3+}$ emission and $\mathrm{Nd}^{3+}$ absorption, there is a very weak $\mathrm{Yb} \rightarrow \mathrm{Nd}$ back transfer, implying the fluorescence emission of $\mathrm{Nd}^{3+}$ is not reflected.

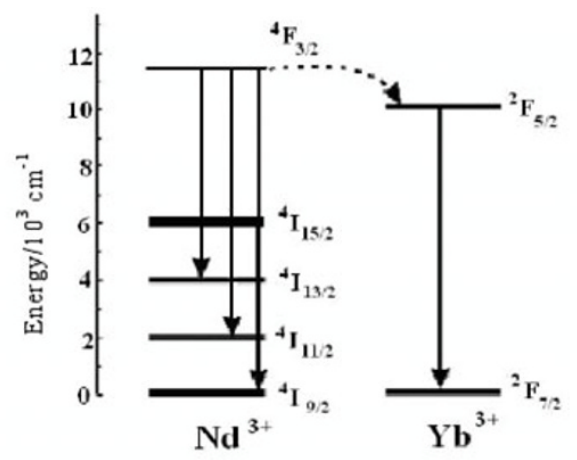

Fig. 7 Scheme of energy transfer for $\mathrm{Nd}^{3+}$ and $\mathrm{Yb}^{3+}$.

\section{Conclusions}

$\mathrm{Nd}, \mathrm{Yb}$ :GGG polycrystalline powders have been successfully synthesized by co-precipitation method. After annealed at $900{ }^{\circ} \mathrm{C}$, the particles of the $\mathrm{Nd}, \mathrm{Yb}$ :GGG polycrystalline powders showed an irregular shape and the average diameter was $68.74 \mathrm{~nm}$. The fluorescence analysis revealed that the strongest emission peak (at $1030 \mathrm{~nm}$ ) of $\mathrm{Nd}, \mathrm{Yb}$ :GGG polycrystalline powders, which was attributed to the transition of ${ }^{2} \mathrm{~F}_{5 / 2} \rightarrow{ }^{2} \mathrm{~F}_{7 / 2}$ of $\mathrm{Yb}^{3+}$.

\section{References}

[1] Chenais S, Druon F, et al. Diode-pumped Yb:GGG laser: Comparison with Yb:YAG. Optical Materials 2003, 22: 99-106.

[2] Yoshida K, Yoshida H. Characterization of high 
average power Nd:GGG slab lasers. IEEE Journal of Quantum Electronics 1988, 24: 1188-1192.

[3] Lacovara PA, Choi HK, Wang CA, et al. Room-temperature diode-pumped Yb:YAG lasers. Opt Lett 1991, 16: 1089-1091.

[4] Belovolov MI, Dinao EM, Timoschechkin MI, et al. Room temperature $\mathrm{Cw}$ Yb:GGG laser operation at 1038-/splmu/m. Conference on Lasers and Electro-optics Europe 1996: 43.

[5] Sun J, Zeng FM, Li JL, et al. Synthesis of Nd: GGG laser ceramics powder by sol-gel combustion method. Journal of Synthetic Crystal 2007, 4: 935.

[6] Zhao GJ, Li T, He XM, et al. Preparation of gadolinium gallium garnet polycrystalline material by coprecipitation method. Materials Letters 2002, 56: 1098-1102.

[7] DeLoach LD, Payne SA, Chase LL, et al. Evaluation of absorption and emission properties of $\mathrm{Yb}^{3+}$ doped crystals for laser applications. IEEE Journal of Quantum Electronics 1993, 29: 1179-1191.

[8] Baney DM, Rankin G, Chang KW. Simultaneous blue and green upconversion lasing in a laser-diode-pumped $\mathrm{Pr}^{3+} / \mathrm{Yb}^{3+}$ doped fluoride fiber laser. Appl Phys Lett 1996, 69: 1662-1664.

[9] Qiu HW, Yang PZ, Dong J, et al. The influence of Yb concentration on laser crystal Yb:YAG. Materials Letters 2002, 55: 1-2.

[10] Jiang BX, Zhao ZW, Xu XD, et al. Spectral properties and charge transfer luminescence of $\mathrm{Yb}^{3+}: \mathrm{Gd}_{3} \mathrm{Ga}_{5} \mathrm{O}_{12}$ (Yb:GGG) crystal. Journal of Crystal Growth 2005, 277: 186-191.

[11] Dexter DL. A theory of sensitized luminescence in solids. Chem Phys 1953, 21: 836. 